\title{
Inherited Metabolic Diseases as a Multisystem Model of Mental Disorders Research
}

Journal of Inborn Errors of Metabolism \& Screening 2021, Volume 9: e20200015 DOI: https://doi.org/10.1590/2326-4594JIEMS-2020-0015

\author{
Grigory Rukavishnikov $^{1}$ (D), Evgeny Kasyanov ${ }^{1}$ (D), Tatiana Zhilyaeva ${ }^{2}$ (D), \\ Nikolay Neznanov ${ }^{1,3}$ (D) and Galina Mazo' ${ }^{1}$
}

\begin{abstract}
Recent biological and genetic research data confirm shared pathological mechanisms of inherited metabolic diseases and mental disorders. We suggest that for further research a model of synergistic heterozygosity can become a convenient tool. In that case the use of inherited metabolic disorders as a multisystem research model can provide both significant theoretical and practical results. At the initial stage of this hypothesis evaluation, it seems efficient to screen for mental symptoms the families of patients with inherited metabolic disorders.
\end{abstract}

Keywords: inherited metabolic disorders, mental disorders, multisystem model, genetic risks.

The study of mental disorders in patients with inherited metabolic disorders (IMD) has recently become the object of intensive research. Patients with IMD are frequently diagnosed with mental disorders in adulthood. Moreover, mental symptoms in such cases are often isolated for many years before the manifestation of more specific metabolic ones. This was shown by a retrospective evaluation of patients with various IMD (Wilson's disease, Niemann-Pick disease type C, acute porphyria and cerebrotendinous xanthomatosis)[1,2]. Phenomenologically, mental symptoms in patients with IMD can fit into the diagnostic criteria of common mental disorders, such as schizophrenia, affective disorders, OCD, personality disorders[3] (for most common variants of mental disorders in different IMD see Table 1).

Thus, standard psychiatric therapeutic strategies are chosen for these patients, and the question of additional laboratory tests does not arise until further multisystemic manifestations. However, in case the diagnosis of the disease "at the psychiatric stage" corresponds to a relatively early phase of the IMD manifest, early specific treatment can provide maximum effectiveness[1], which determines the importance of the mental status evaluation in patients with IMD.

On the other hand, the diagnosis of IMD in patients with mental disorders during metabolic screening is high even for orphan diseases. Thus, the prevalence of acute intermittent porphyria (AIP) in patients with mental disorders is 20 times higher than in the general population[4]. In patients with mental disorders, as well as in IMD, systemic disorders of the connective tissue are more prevalent than in the general population[5]. There is strong evidence for an association of joint hypermobility syndrome with a wide range of mental disorders[6]. This suggests shared etiopathogenetic mechanisms of mental disorders with a number of hereditary syndromes of connective tissue dysplasia (Ehlers-Danlos, Marfan), and also indicates the systemic nature of the pathological process in mental disorders. The probable association of IMD with mental disorders is also confirmed by the results of new generation sequencing family studies. The findings suggest a potential phenotypic burden of rare genetic variants for mendelian monogenic diseases and pleiotropic effects in the etiology of multifactorial mental disorders[7].

The mechanisms of multifactorial diseases cannot be reduced to a single genetic variant. Dysfunctions of genes at several loci

\footnotetext{
'V. M. Bekhterev National Medical Research Center for Psychiatry and Neurology, Bekhterev st. 3, Saint-Petersburg, 192019, Russian Federation.

${ }^{2}$ Privolzhsky Research Medical University, Minin and Pozarsky sq. 10/1, Nizhny Novgorod, 603005, Russian Federation.

${ }^{3}$ I. P. Pavlov First Saint-Petersburg State Medical University, Lev Tolstoy st. 6-8, Saint-Petersburg, 197022, Russian Federation.
}

Received October 05, 2020, and in revised form January 09, 2021. Accepted for publication January 22, 2021.

\section{Corresponding Author:}

Grigory Rukavishnikov, V.M. Bekhterev National Medical Research Center for Psychiatry and Neurology, Bekhterev st. 3, Saint-Petersburg, 192019, Russian Federation.

Email: grigory_v_r@mail.ru 
Table 1. Mental disorders in different types of IMD[1-3].

\begin{tabular}{|c|c|c|c|}
\hline IMD & Genes affected & Mental pathology mechanisms & Mental disorders \\
\hline Hyperhomocysteinemia & $\begin{array}{l}\text { CBS, MTHFR, MTR, } \\
\text { MTRR, MMADHC }\end{array}$ & $\begin{array}{l}\text { Increased homocysteine levels; decrease } \\
\text { in Sadenosylmethionine synthesis; NMDA } \\
\text { receptors agonism; neurotoxic effects on } \\
\text { dopaminergic neurons }\end{array}$ & $\begin{array}{l}\text { Major depressive disorder } \\
\text { schizophrenia, cognitive decline, } \\
O C D \text { - in nearly } 50 \% \text { of cases }\end{array}$ \\
\hline Prader-Willi syndrome & $\begin{array}{c}\text { Deletion } 15 q 11.2-q 13 \text {, maternal } \\
\text { isodiosmy upd(15)mat, pathological } \\
\text { imprinting }\end{array}$ & No sufficient data & $\begin{array}{l}\text { Schizophrenia-like psychosis (10-30\%), } \\
\text { OCD spectrum disorders (71\%), mental } \\
\text { retardation (50-65\%), major depressive } \\
\text { disorder (23\%), bipolar disorder (10\%) }\end{array}$ \\
\hline Fabry disease & GLA & Alpha-galactosidase A dificiency & $\begin{array}{c}\text { Major depressive disorder (46-58\%), } \\
\text { anxiety/panic attacks (39\%), ADHD (24\%) }\end{array}$ \\
\hline Niemann-Pick diseases & SMPD1, NPC1, NPC2 & Accumulation of sphingomyelin & $\begin{array}{c}\text { Cognitive decline (90\%), psychosis (62\%), } \\
\text { affective disorders (38\%) }\end{array}$ \\
\hline Lesch-Nyhan syndrome & $\begin{array}{c}\text { Long shoulder of } \\
\text { X-chromosome of HPRT gene }\end{array}$ & Dysfunction of HPRT enzyme & $\begin{array}{l}\text { Cognitive decline, inadequate behavior, } \\
\text { autoaggression, aggression }\end{array}$ \\
\hline
\end{tabular}

Decreased activity of BCKDH complex; decreased degradation of the branchedchain amino acids; hyperleucinemia inhibits tyrosine, tryptophan and other essential aminoacids transport through hematoencephalic barrier restricting substrate for serotonin synthesis

Altered cooper transportation by cerulloplasmin

Wilsons disease

ATP7B

HMBS

Acute intermittent porphyria

Partial deficiency of the enzyme hydroxymethylbilane synthase

Increase in phenylalanine levels, decrease in tetrahydrobiopterin $(\mathrm{BH} 4)$

Phenylketonuria

PAH

CPS1, OTC, ASS1, ASL, ARG1, NAGS
Ammonia metabolism defects, ammonia and other metabolites accumulation
Emotional lability, impulsivity, sexual deviations, major depressive disorder, schizophrenia-like psychosis, catatonic symptoms - in $10-20 \%$ of cases (more prevalent in neuro type)

Depressive and anxiety disorders, insomnia, anorexia - 80-99\% of cases; hallucinations 5-29\%; psychosis - $1 \%$

Mental retardation - 30-79\%; anxiety and depressive disorders, aggressive behavior 5-29\%; ADHD, OCD, psychosis - $1 \%$

\footnotetext{
Hallucinations, atypical depression, schizophrenia-like psychosis
}

lead to polygenic multifactorial diseases. From these positions, metabolic medicine is a bridge for the transition in the study from well-known multisystem monogenic diseases to multisystem polygenic diseases. For the further hypotheses, a model of synergistic heterozygosity can become a convenient tool, which is a special example of epistasis or multifactorial inheritance, when multiple loci (heterozygous for harmful mutations in the genes of the metabolic pathway) interact, forming a phenotype that is realized under the impact of stress or environmental factors $[8,9,10]$.
The question is: can a heterozygous mutation, if it does not lead to a full clinical IMD, become a predisposing factor for the mental disorders? Unlike homozygous carriers, clinical signs are not obvious in heterozygotes, although a biochemical phenotype can be found[11]. This suggests that heterozygotes have a not critical, but possibly a significant decrease in several enzymes, which can affect at certain stages the risk of and the course of mental and somatic disorders.

The development of cell biology has made it possible to change the attitude towards heterozygotes for Mendelian diseases. It is 
assumed that in heterozygotes, the normal alleles are protective against the expected IMD phenotype, while the mutated allele acts as a risk factor for another disease process $[9,10]$. At the same time, there are few published studies with very variable methodology examining the heterozygous mutations in IMD genes in patients with mental disorders. Thus, to support this hypothesis, at the initial stage, it is efficient to screen for mental symptoms in the families of patients with IMD.

Today, the study of the possible pathogenetic association of IMD with mental disorders remains a poorly studied area both in psychiatry and metabolic diseases. But the combination of the competencies of these two medical areas can give both theoretical and practical results. The use of metabolic screening algorithms for the diagnosis of mental disorders is a promising direction that will allow detecting IMD in the early stages and ensure the introduction of substitution therapy before the onset of metabolic decompensations. On the other hand, metabolic screening can change the diagnostic process in psychiatry and make it possible to identify specific biotypes of mental disorders which treatment with enzyme replacement therapy can become the object of research.

\section{Funding}

The research is supported by the Russian Foundation of Basic Research grant \#19-015-00420.

\section{Declaration of Conflicting Interests}

The authors declared no potential conflicts of interest with respect to the research, authorship, and/or publication of this article.

\section{References}

1. Baeza-Velasco C, Pailhez G, Bulbena A, Baghdadli A. Joint hypermobility and the heritable disorders of connective tissue: clinical and empirical evidence of links with psychiatry. Gen Hosp Psychiatry. 2015;37(1):24-30. doi: 10.1016/j.genhosppsych.2014.10.002

2. Demily C, Sedel F. Psychiatric manifestations of treatable hereditary metabolic disorders in adults. Ann Gen Psychiatry. 2014;13:27. doi: 10.1186/s12991-014-0027-x
3. Estrov Y, Scaglia F, Bodamer OA. Psychiatric symptoms of inherited metabolic disease. J Inherit Metab Di. 2020;23(1):2-6. doi: 10.1023/a:1005685010766

4. Ganesh S, Ahmed PH, Nadella RK, et al. Exome sequencing in families with severe mental illness identifies novel and rare variants in genes implicated in Mendelian neuropsychiatric syndromes. Psychiatry Clin Neurosci. 2019;73(1):11-19. doi: 10.1111/pcn.12788

5. Sedel F, Baumann N, Turpin JC, Lyon-Caen O, Saudubray JM, Cohen D. Psychiatric manifestations revealing inborn errors of metabolism in adolescents and adults. J Inheri Metab Dis. 2007;30:631-641. doi: 10.1007/s10545-0070661-4

6. Sidransky E. Heterozygosity for a Mendelian disorder as a risk factor for complex disease. Clin Genet. 2006;70(4):27582. doi: 10.1111/j.1399-0004.2006.00688.x

7. Stegink LD, Koch R, Blaskovics ME, Filer LJ Jr, Baker GL, McDonnell JE. Plasma phenylalanine levels in phenylketonuric heterozygous and normal adults administered aspartame at $34 \mathrm{mg} / \mathrm{kg}$ body weight. Toxicology. 1981;20(1):81-90. doi: 10.1016/0300$483 \mathrm{x}(81) 90108-6$

8. Tishler PV, Woodward B, O'Connor J, Holbrook DA, Seidman LJ, Hallett M, Knighton DJ. High prevalence of intermittent acute porphyria in a psychiatric patient population. Am J Psychiatry. 1985;142(12):1430-1436. doi: 10.1176/ajp.142.12.1430

9. Vockley J, Rinaldo P, Bennett MJ, Matern D, Vladutiu GD. Synergistic Heterozygosity: Disease Resulting from Multiple Partial Defects in One or More Metabolic Pathways. Mol Genet Metab. 2000;71(1-2):10-18. doi: 10.1006/mgme.2000.3066

10. Vockley J. Metabolism as a complex genetic trait, a systems biology approach: implications for inborn errors of metabolism and clinical diseases. J Inherit Metab Dis. 2008;31(5):619-629. doi: 10.1007/s10545-008-1005-8

11. Xu T, Chan RCK, Compton MT. Minor physical anomalies in patients with schizophrenia, unaffected first-degree relatives, and healthy controls: a meta-analysis. PLoS One. 2011;6(9):e24129. doi: 10.1371/journal.pone.0024129 